\title{
Insights into the metabolism, lifestyle and putative evolutionary history of the novel archaeal phylum 'Diapherotrites'
}

\author{
Noha H Youssef ${ }^{1}$, Christian Rinke ${ }^{2}$, Ramunas Stepanauskas ${ }^{3}$, Ibrahim Farag ${ }^{1}$, Tanja Woyke ${ }^{2}$ \\ and Mostafa S Elshahed ${ }^{1}$ \\ ${ }^{1}$ Department of Microbiology and Molecular Genetics, Oklahoma State University, Stillwater, OK, USA; \\ ${ }^{2}$ DOE Joint Genome Institute, Walnut Creek, CA, USA and ${ }^{3}$ Bigelow Laboratory for Ocean Sciences, \\ East Boothbay, ME, USA
}

\begin{abstract}
The archaeal phylum 'Diapherotrites' was recently proposed based on phylogenomic analysis of genomes recovered from an underground water seep in an abandoned gold mine (Homestake mine in Lead, SD, USA). Here we present a detailed analysis of the metabolic capabilities and genomic features of three single amplified genomes (SAGs) belonging to the 'Diapherotrites'. The most complete of the SAGs, Candidatus 'lainarchaeum andersonii' (Cand. IA), had a small genome ( $\sim 1.24 \mathrm{Mb})$, short average gene length (822 bp), one ribosomal RNA operon, high coding density $(\sim 90.4 \%)$, high percentage of overlapping genes $(27.6 \%)$ and low incidence of gene duplication (2.16\%). Cand. IA genome possesses limited catabolic capacities that, nevertheless, could theoretically support a free-living lifestyle by channeling a narrow range of substrates such as ribose, polyhydroxybutyrate and several amino acids to acetyl-coenzyme A. On the other hand, Cand. IA possesses relatively well-developed anabolic capabilities, although it remains auxotrophic for several amino acids and cofactors. Phylogenetic analysis suggests that the majority of Cand. IA anabolic genes were acquired from bacterial donors via horizontal gene transfer. We thus propose that members of the 'Diapherotrites' have evolved from an obligate symbiotic ancestor by acquiring anabolic genes from bacteria that enabled independent biosynthesis of biological molecules previously acquired from symbiotic hosts. 'Diapherotrites' 16S rRNA genes exhibit multiple mismatches with the majority of archaeal 16S rRNA primers, a fact that could be responsible for their observed rarity in amplicon-generated data sets. The limited substrate range, complex growth requirements and slow growth rate predicted could be responsible for its refraction to isolation.
\end{abstract}

The ISME Journal (2015) 9, 447-460; doi:10.1038/ismej.2014.141; published online 1 August 2014

\section{Introduction}

Our view of the phylogenetic diversity and ecological distribution of members of the domain Archaea is rapidly evolving. Historically, Archaea were regarded as a collection of extremophiles that could only thrive in extreme habitats, for example, high temperature (Huber et al., 1991; Jannasch et al., 1992; Antoine et al., 1995; Whitaker et al., 2003), high salinity (Oren et al., 1990; Cui et al., 2010; Goh et al., 2011; Inoue et al., 2011), low pH (Edwards et al., 2000; Dopson et al., 2004), strict anaerobic conditions (Mikucki et al., 2003; Sakai et al., 2007) or combinations thereof (Huber et al., 1989; Itoh et al., 1999; Minegishi et al., 2008, 2013).

Correspondence: NH Youssef, Department of Microbiology and Molecular Genetics, Oklahoma State University, $1110 \mathrm{~S}$ Innovation Way Drive, Stillwater, OK 74074, USA.

E-mail:noha@okstate.edu

Received 1 May 2014; revised 22 June 2014; accepted 1 July 2014; published online 1 August 2014
This notion was subsequently challenged by culture-independent diversity surveys that documented the occurrence of the Archaea in both extreme (Bond et al., 2000; Orphan et al., 2000; Benlloch et al., 2001, 2002; Baker and Banfield, 2003) and temperate habitats, for example, soil (Bintrim et al., 1997; Walsh et al., 2005; Bates et al., 2011; Tripathi et al., 2013), marine environments (DeLong, 1992; Fuhrman et al., 1992; Massana et al., 1997; Karner et al., 2001) and freshwater ecosystems (Lin et al., 2012; Yergeau et al., 2012; Berdjeb et al., 2013; Bricheux et al., 2013; Silveira et al., 2013; Vila-Costa et al., 2013). In addition to establishing the ubiquity of the Archaea on a global scale, these studies have also significantly expanded the scope of phylogenetic diversity within this domain, as many of the sequences identified represented novel, high-rank phylogenetic lineages (DeLong, 1992; Vetriani et al., 1999; Takai et al., 2001; Hallam et al., 2004; Elkins et al., 2008; Hu et al., 2011; Nunoura et al., 2011). 
Environmental genomic approaches and dedicated isolation efforts have yielded valuable insights into the metabolic capabilities and ecological roles of many of these novel lineages (Hallam et al., 2004; Konneke et al., 2005; Elkins et al., 2008; Walker et al., 2010; Lloyd et al., 2013). Recently, the pace of discovery and characterization of archaeal lineages has significantly accelerated, driven by recent methodological and computational advances in single cell sorting and amplification, sequencing methodologies and novel binning and assembly approaches that enable efficient genomic reconstruction from metagenomic sequence data (Dick et al., 2009; Wrighton et al., 2012; Rinke et al., 2013; Swan et al., 2013). These advances led to the identification and genomic characterization of multiple novel high-rank archaeal lineages that have previously escaped detection in $16 \mathrm{~S}$ ribosomal RNA (rRNA) gene-based diversity surveys because of their extremely low relative abundance, limited distribution or mismatches to archaeal 16S rRNA gene primer sequences (Baker et al., 2010; Nunoura et al., 2011; Narasingarao et al., 2012). These discoveries necessitated phylogenetic and phylogenomic-based reassessment of the taxonomic structure of the domain Archaea (Lake et al., 1984; BrochierArmanet et al., 2008; Elkins et al., 2008; Ghai et al., 2011; Guy and Ettema, 2011; Williams et al., 2012). The most recent and comprehensive phylogenomicsbased assessment of the domain Archaea (Rinke et al., 2013) combined data from 35 novel archaeal single amplified genomes (SAGs) with previously published archaeal genomes to propose a three archaeal superphyla scheme. These superphyla are the Euryarchaeota, the TACK superphylum (encompassing the Thaumarchaeota, 'Aigarchaeota', Crenarchaeota and Korachaeota as previously suggested; Guy and Ettema, 2011; Williams et al., 2012) and the newly proposed DPANN superphylum.

The DPANN superphylum encompasses the 'Nanoarchaeota' (Waters et al., 2003; Podar et al., 2013), the only DPANN phylum with cultured representatives, as well as the candidate phyla 'Nanohaloarchaeota' (defined from metagenomic assembly (Narasingarao et al., 2012) and SAGs (Ghai et al., 2011) from hypersaline environments); 'Parvarchaeota' (defined from a metagenomic assembly from an acid mine drainage; Baker et al., 2010), 'Aenigmarchaeota' (defined from three SAGs from Homestake mine groundwater seep (Lead, SD, USA) and the Great Boiling Spring sediments; Rinke et al., 2013) and 'Diapherotrites' (defined from SAGs from Homestake mine groundwater seep; Rinke et al., 2013). As such, the DPANN superphylum represents an intriguing collection of phyla with disparate physiological preferences and environmental distribution, ranging from the obligatory symbiotic and thermophilic species within the 'Nanoarchaeota', to the acidophilic candidate phylum 'Parvarachaeota' and to the non-extremophilic candidate phyla 'Aenigmarchaeota' and 'Diapherotrites'.
Here, we present a detailed analysis of the genomic, metabolic and ecological features of three SAGs belonging to the 'Diapherotrites'. We present evidence of genomic streamlining as well as limited metabolic capacities within the analyzed genomes. We also demonstrate the prevalence of crosskingdom horizontal gene transfer (HGT) events, and argue that HGT process represents an important evolutionary mechanism that contributes to the observed genomic features, ecological distribution and proposed trophic lifestyle of members of this phylum.

\section{Materials and methods}

Origin of Diapherotrites SAGs

Candidate phylum 'Diapherotrites' (CP-'Diapherotrites') SAGs analyzed in this study were all obtained from a groundwater seep from the ceiling of Homestake Mine (Lead, SD, USA) drift at a depth of $100 \mathrm{~m}$ as described previously (Rinke et al., 2013). Cell sorting and lysis, single-cell whole genome amplification, 16S rRNA amplicon sequencing as well as SAG sequencing and assemblies have been detailed before (Rinke et al., 2013). Three CP-'Diapherotrites' SAGs were deposited under Genbank assembly IDs GCA_000402355.1, GCA_000404545.1 and GCA_000404525.1, and Integrated Microbial Genomes (IMG) SAG names SCGC_AAA011-E11, SCGC_AAA011-K09 and SC GC_AAA011-N19. The candidatus-type species for CP-'Diapherotrites' is the SAG SCGC_AAA011-E11, for which the name Candidatus 'Iainarchaeaum andersonii' was proposed (Rinke et al., 2013). Our analysis was mainly conducted on the Candidatus Iainarchaeaum andersonii genome (henceforth referred to as Cand. IA), as it had the highest estimated genome completion $(88.5 \%)$ among the three CP-'Diapherotrites' genomes (Supplementary Table S1), with the other two partial SAGs mainly used for confirmatory purposes.

\section{Genome annotation, general genomic features and metabolic reconstruction}

Genome functional annotation was performed using the IMG platform (http://img.jgi.doe.gov) as previously described (Rinke et al., 2013). Metabolic reconstruction was conducted using both KEGG (Kyoto Encyclopedia of Genes and Genomes) and Metacyc databases (Kanehisa, 2002; Karp et al., 2002). Proteases, peptidases and protease inhibitors were predicted using Blastp against the Merops database (Rawlings et al., 2014). Transporters were identified by querying the genome against the TCDB (transporter classification database) (Saier et al., 2014) using Blastp (Altschul et al., 1990). Gene duplications were identified by running local Blastp using the proteins as both the subject and the query, where non-self hits with a similarity cutoff of $>90 \%$ are considered duplicates. Overlapping genes were 
identified by comparing the coordinates of the start and stop codons for all genes on the same contig. Protein subcellular localizations were identified online using the PSORTb V 3.0.2 (Yu et al., 2010). Protein COG (Cluster of orthologous groups; Tatusov et al., 2000) family distributions for Cand. IA and reference genomes were either obtained from the corresponding IMG genome page or, in case the genome was not available in the IMG database, were identified using the web batch conserved domain (Marchler-Bauer et al., 2010) search tool (available at http://www.ncbi.nlm.nih.gov/Structure/bwrpsb/ bwrpsb.cgi) against the COG database with an $E$-value threshold of 0.001 .

\section{HGT in Cand. IA genome assembly}

A two-tier approach was utilized to evaluate the putative frequency of occurrence of HGT in Cand. IA genome assembly. Blastp (Altschul et al., 1990) was conducted for all genes in Cand. IA as well as other representatives of the DPANN superphylum. Genes were classified according to the Blastp first hit. For in-depth evaluation of HGT within Cand. IA, 21 HGT candidate genes with bacterial Blastp first hit were chosen for further analysis according to the following two criteria: (1) protein length is longer than 100 amino acids and (2) placement on a contig with other genes involved in the same pathway but of apparent archaeal origin. In cases where all genes involved in a pathway had bacterial Blastp first hit, priority was for genes present on longer contigs with other genes of apparent archaeal origin. Homologs of genes of interest were obtained from Genbank by BLASTP of the target gene. The obtained homolog data sets were comparatively aligned using COBALT (Papadopoulos and Agarwala, 2007). A guide tree was used to select the closest relatives of the target gene. In cases where all the closest relatives belonged to bacterial phyla, archaeal counterparts were obtained from Genbank and included in the downstream analysis. A eukaryotic outgroup was also included. For phylogenetic tree construction, target genes and their homologs were aligned using ClustalW (Larkin et al., 2007). Maximum likelihood trees were calculated from the alignment using the BLOSUM62 model and GAMMA approximation implemented in RaxML (Stamatakis, 2014).

\section{Principal component analysis (PCA)}

PCA was conducted to identify salient differences in genomic features and COG distributions between DPANN and other model archaeal genomes. A list of genomes, as well as features used in this analysis, is presented in Supplementary Table S2. Initially, all genomic features previously implied as determinants of genome streamlining (Giovannoni et al., 2005; Lauro et al., 2009; Swan et al., 2013) were included in the analysis. These include: genome size, number of genes, GC content, noncoding density, number of ribosomal RNA operons, percentage of transporter proteins per genome size, COG categories distribution (that is, percentage of proteins belonging to each COG category), protein sublocalization (percentage of proteins destined to the cytoplasm, cytoplasmic membrane, cell wall and extracellular milieu) and encoded amino acid frequency. Data were then implemented in the PCA using the prcomp function in the labdsv package (Roberts, 2012) of R (R Development Core Team, 2008). A biplot was constructed using the biplot function in $\mathrm{R}$, where genomes are represented as points and variables are represented as arrows pointing in the direction of maximal abundance ( $\mathrm{R}$ Development Core Team, 2008). To simplify the biplots, all variables that showed minimal effect on the PCA biplots (for example, variables whose arrows clustered at the origin) were removed and the analysis was repeated.

Mismatches in CP-'Diapherotrites' $16 S$ rRNA genes to archaeal primers and secondary structure prediction 16S rRNA genes from the three CP-'Diapherotrites' SAGs were aligned to reference small subunit rRNA sequences, and sites of universal archaeal primers previously utilized in culture-independent surveys were examined to identify putative mismatches and/or indel occurrences. Secondary structure prediction was achieved using the Mfold web server (Zuker, 2003), with the minimum energy structure predicted compared with the conserved secondary structure of both the Escherichia coli and Methanospirilum hungatei 16S rRNA molecules.

Mining public databases to elucidate the distribution of the 'Diapherotrites' in nature

We attempted to identify the occurrence of members of the CP-'Diapherotrites' in various ecosystems by mining metagenomic data sets in the IMG database $(n=893$, accessed in December 2013), Sangergenerated 16S rRNA gene sequences in the $\mathrm{nr}$ database ( $n=5365062$ sequences, accessed in January 2014) and partial, high-throughput (pyrosequencing and Illumina)-generated archaeal 16S rRNA gene sequences in MG-RAST (Meyer et al., 2008) and SRA archive (Leinonen et al., 2011) $(n=31972882$ sequences in 775 data sets generated using archaeal primers). Identification of CP-'Diapherotrites' in metagenomic data sets was conducted using the three 'Diapherotrites' SAG assemblies for anchoring metagenomic reads as previously described (Rinke et al., 2013). To identify the distribution using data in Sanger- and high-throughput-generated data sets, we followed the protocols previously described in Farag et al. (2014).

\section{Results}

General features of 'Diapherotrites' genomes

The general features of Cand. IA partial genome compared with sequenced representatives of the 
Table 1 Genomic features of Candidatus 'Iainarchaeum andersonii' genome compared with other DPANN superphylum members

\begin{tabular}{|c|c|c|c|c|c|}
\hline $\begin{array}{l}\text { Phylum } \\
\text { Genome }\end{array}$ & $\begin{array}{l}\text { Diapherotrites } \\
\text { Candidatus } \\
\text { 'Iainarchaeum } \\
\text { andersonii' }\end{array}$ & $\begin{array}{l}\text { Nanoarchaeota } \\
\text { Nanoarchaeum } \\
\text { equitans } \\
\text { Kin-4 }\end{array}$ & $\begin{array}{l}\text { Parvarchaeota } \\
\text { Candidatus } \\
\text { 'Micrarchaeum } \\
\text { acidiphilum' } \\
\text { ARMAN-2 }\end{array}$ & $\begin{array}{l}\text { Nanohaloarchaeota } \\
\text { Candidatus } \\
\text { 'Nanosalina'sp. } \\
\text { J07AB43 }\end{array}$ & $\begin{array}{l}\text { Aenigmarchaeota } \\
\text { Candidatus } \\
\text { 'Aenigmarchaeum } \\
\text { subterraneum' }\end{array}$ \\
\hline Genome size, $\mathrm{Mb}$ & 1.1 & 0.49 & $\sim 1$ & 1.23 & 0.43 \\
\hline Genome completeness (\%) & 88.5 & 100 & $\sim 99$ & $\sim 100$ & 47.3 \\
\hline Estimated size $(\mathrm{Mb})$ & 1.24 & 0.49 & 1 & 1.23 & 0.91 \\
\hline GC \% & 47 & 31.6 & 47.2 & 44 & 38.6 \\
\hline$\%$ Noncoding & 9.56 & 7.6 & 9.3 & 12.4 & 5.24 \\
\hline \% Overlapping genes & 27.63 & 44.1 & $18-19$ & 24.9 & 19.42 \\
\hline Gene duplication ${ }^{\mathrm{a}}(\%)$ & 2.16 & ND & ND & ND & ND \\
\hline Average gene length, bp & 822 & 827 & 892 & 639 & 766 \\
\hline \multicolumn{6}{|l|}{ RNA genes } \\
\hline 5S rRNA count & 0 & 1 & 0 & 1 & 2 \\
\hline 16S rRNA count & 1 & 1 & 1 & 1 & 1 \\
\hline 23S rRNA count & 1 & 1 & 1 & 0 & 0 \\
\hline tRNA count & 39 & 38 & 35 & 59 & 36 \\
\hline Number of CDS & 1202 & 556 & 1033 & 1678 & 525 \\
\hline With function prediction & 782 & 549 & 668 & 773 & 308 \\
\hline Without function prediction & 420 & 7 & 365 & 905 & 217 \\
\hline Number of CDS with inteins & 5 & 1 & 1 & 1 & 0 \\
\hline $\begin{array}{l}\text { Number of CDS with IS } \\
\text { elements }\end{array}$ & 24 & 0 & 10 & 9 & 3 \\
\hline Number of paralog clusters & 156 & 53 & ND & 198 & 220 \\
\hline \multicolumn{6}{|l|}{$\%$ Of proteins sublocalized to } \\
\hline Cytoplasm & 79.9 & 63.3 & 65.6 & 68.9 & 61.5 \\
\hline Cytoplasmic membrane & 14.6 & 12.3 & 18.9 & 12.8 & 19.23 \\
\hline Extracellular milieu & 1.4 & 0.8 & 1.2 & 2.3 & 1.7 \\
\hline
\end{tabular}

Abbreviations: CDS, coding sequence; IS elements, insertion sequence elements; ND, not determined; rRNA, ribosomal RNA; tRNA, transfer RNA.

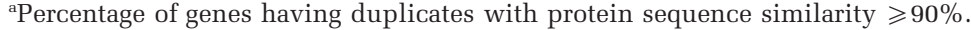

DPANN superphylum are shown in Table 1. Cand. IA exhibits general genomic features previously observed in DPANN genomes (Baker and Banfield, 2003; Waters et al., 2003; Narasingarao et al., 2012; Rinke et al., 2013). It has a relatively small genome (estimated size $\sim 1.24 \mathrm{Mb}$ ), short average gene length (822 bp), single ribosomal RNA operon, high coding density $(\sim 90.4 \%)$, high percentage of overlapping genes $(27.6 \%$, mean overlap $4 \mathrm{bp}$, range $1-12 \mathrm{bp}$ ) and very low incidence of gene duplication $(2.16 \%)$.

\section{Metabolic features of Cand. IA}

Catabolic capacities. Analysis of Cand. IA genome suggests that it possesses a relatively limited catabolic potential. The genome lacks evidence for a complete glycolysis, tricarboxylic acid cycle or short-chain fatty acid or alcohol degradation. Nevertheless, the genome suggests the capability to channel few distinct substrates (valine, alanine, aspartate, ribose and polyhydroxybutyrate) into acetyl- (or acyl-) coenzyme A (CoA), and subsequently generate adenosine triphosphate (ATP) via acetyl-CoA synthase (Figure 1). Details of the pathways involved in these processes are provided in the Supplementary Text. In brief, for amino acid degradation, the genome harbors multiple transaminases that allow for the conversion of alanine, valine and aspartate to the corresponding 2-oxoacids. Oxidative decarboxylation of the 2-oxoacids to acylCoA can occur via pyruvate/2-oxoacid:ferredoxin oxidoreductases, or oxaloacetate-decarboxylating malate dehydrogenase (EC: 1.1.1.38) followed by conversion into the corresponding free acid via acyl-CoA synthetase with the concurrent production of 1 ATP. An incomplete tricarboxylic acid cycle could potentially replenish 2-ketoglutarate for the transamination reactions.

Cand. IA also appears to possess the capability for ribose degradation (Figure 1), where ribose could potentially be activated by ribokinase and ribose5 -phosphate pyrophosphokinase. The presence of type III ribulose-1,5-bisphosphate carboxylase (Rubisco) in Cand. IA genome suggests the employment of the novel adenosine monophosphate (AMP) metabolism pathway suggested by Aono et al. (2012). The combination of ribose activation and AMP salvage enzymes eventually lead to the production of 3-phosphoglycerate that feeds into the lower arm of glycolysis and subsequently leads to ATP production as described above. The process results in a net production of $2 \mathrm{ATP} /$ ribose (Supplementary Text).

Another potential carbon and energy source for Cand. IA is polyhydroxybutyrate (PHB), the storage compounds produced by many bacteria under 


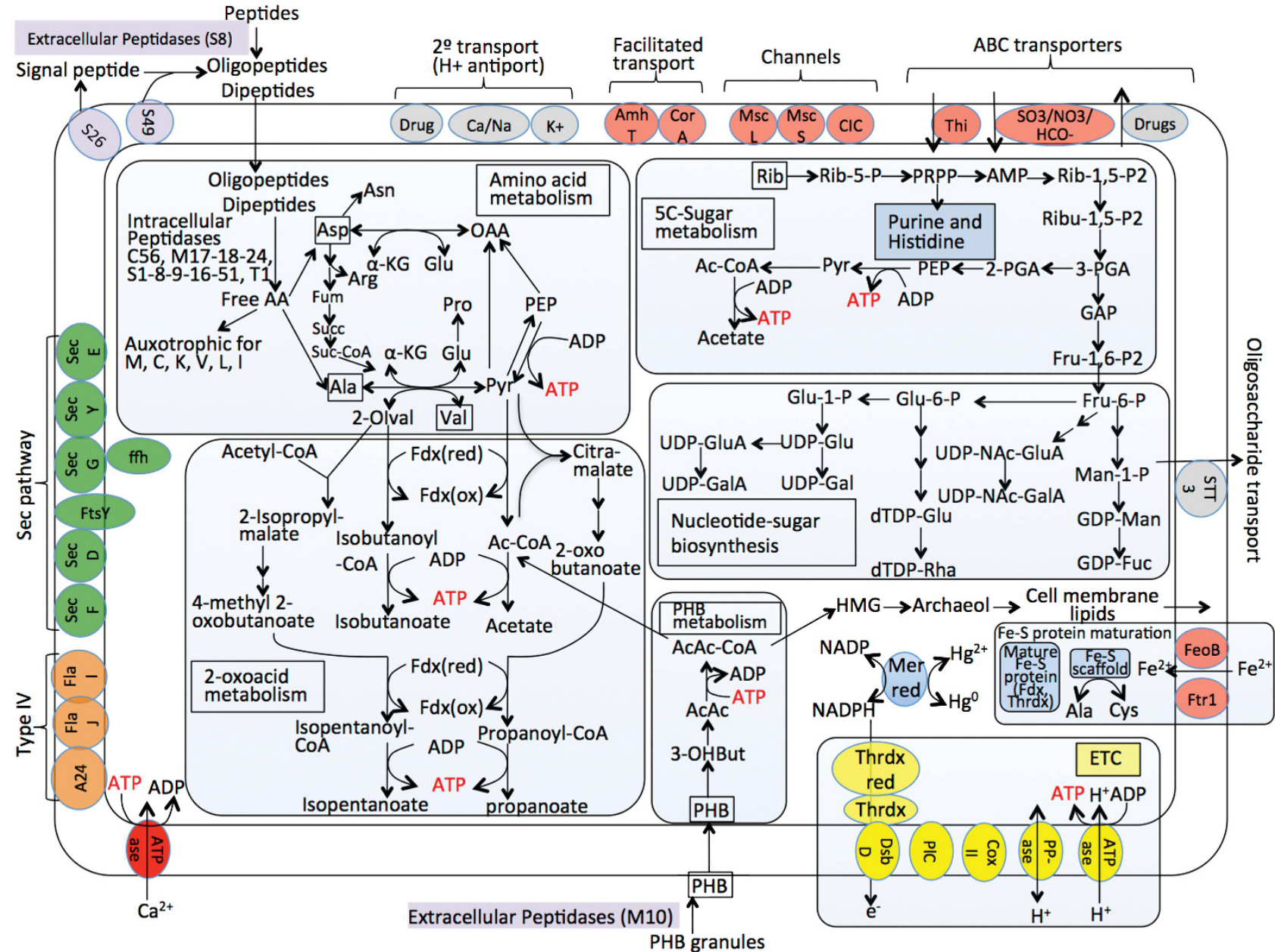

Figure 1 Metabolic reconstruction for Candidatus Iainarchaeum andersonii genome. Double lines surrounding the cell depict cell membrane. Possible catabolic ATP-producing pathways are shown in light blue boxes, and sites of ATP production are shown in red. Potential substrates are shown in boxes, and include the amino acids alanine, valine and aspartate, the 5C-sugar ribose and polyhydroxybutyrate. AcAc, acetoacetate; AcAc-CoA, acetoacetyl-CoA; Fdx, ferredoxin; 3-OHBut, 3-hydroxybutyrate. Electron transport chain components are shown in yellow. ATPase, V-type ATPase pump; CoxII, cytochrome oxidase subunit II; DsbD, disulfide bond oxidoreductase D; PlC, plastocyanin; PPase, inorganic pyrophosphatase; Thrdx, thioredoxin; Thrdx red, thioredoxin reductase. NADPH could potentially act as the electron donor to the ETC. Possible sites of NADPH production in the cell include mercuric reductase enzyme (Mer Red). All predicted transporters with known functions are shown. (1) Secretory pathways: components of the Sec pathway are shown in green, whereas components of type IV pili assembly are shown in orange. (2) Transporters: exporters are shown in gray including secondary antiporters, ABC transporters, STT3 the oligosaccharide exporter, whereas importers are shown in red including the facilitated transporters AmhT and CorA, the channels of MscS, MscL and ClC families, ABC transport systems for thiamine and sulfonate/nitrate/bicarbonate as well as ferrous iron transporters FeoB and Ftr1 for Fe-S assembly. AmhT, for ammonium; ClC, chloride channel families; CorA, for cobalt; MscL, large mechanosensitive; MscS, small mechanosensitive. Peptidases are shown in purple.

conditions of excess carbon. The genome encodes a PHB depolymerase downstream of, and overlapping with, a transmembrane matrixin-coding gene (peptidase family M10) (Visse and Nagase, 2003; Rawlings et al., 2014), known to hydrolyze extracellular matrix components. Therefore, it appears that matrixin is used by Cand. IA to break down the protein shell of PHB granules, and the released PHB is subsequently depolymerized into $\beta$-hydroxybutyrate. The produced $\beta$-hydroxybutyrate could potentially be oxidized to acetoacetate (using a NAD-dependent dehydrogenase belonging to the GFO/IDH/MOCA family (pfam 01408)), followed by activation of acetoacetate to acetoacetyl-CoA using acyl-CoA synthase. The concerted action of
acetyl-CoA C-acetyltransferase and acetyl-CoA synthetase converts acetoacetyl-CoA to two molecules of acetate with the concomitant production of ATP.

Finally, it is plausible that Cand. IA might also employ a modified electron transport chain, similar to that recently suggested for candidate division TM6 (McLean et al., 2013). The chain will involve disulfide bond oxidoreductase D (DsbD), a thioredoxin-disulfide (NADPH) reductase (EC. 1.8.1.9) and thioredoxins as initial substrate (NADPH) oxidoreductases, plastocyanins as potential cytochrome equivalents and cytochrome $c$ oxidase as a potential terminal oxidase. An inorganic pyrophosphatase and all subunits of V-type ATP synthase 
could potentially employ the proton motive force generated across the membrane for ATP synthesis (Figure 1 and Supplementary Text).

Anabolic potential. Although the catabolic potential of Cand. IA appears to be rather limited, the genome suggests a fairly well-developed anabolic machinery. Cand. IA genome suggests the capacity for biosynthesis of multiple carbohydrates, amino acids, lipids, nucleotides as well as several cofactors (Figure 1, Table 2 and Supplementary Table S3). Cand. IA genome encodes a partial gluconeogenic pathway up to the level of fructose-6-phosphate. The genome shows evidence for synthesizing most amino acids with the exception of lysine, cysteine, methionine and branched chain amino acids (Figure 1 and Table 2). In addition, all enzymes essential for archaeol, the archaeal membrane lipid, biosynthesis from acetyl-CoA via the mevalonate pathway are encoded in the genome. Cand. IA genome shows evidence for biosynthesis of some cofactors (riboflavin, pyridoxal phosphate, nicotinate and nicotinamide, coenzyme A and ferredoxin) and nucleotides (complete evidence for de novo biosynthesis of pyrimidine nucleotides, partial evidence for purines). Finally, all necessary enzymes for assembly of $\mathrm{Fe}-\mathrm{S}$ and maturation of Fe-S proteins are also encoded by the genome.

Transporters and extracellular peptidases. Although the number of transporters encoded by Cand. IA genome are fairly limited $(n=54)$, they appear to be able to uptake several cations and anions (Supplementary Text). Several transporters belonging to transporter families with unidentified substrates are annotated as membrane proteins with unknown function and hence might be involved in the transport of amino acids, sugars or cofactors for which Cand. IA appears to be auxotrophic. The genome also encodes for various extracellular and membrane-associated peptidases (see Supplementary Text for more details) that presumably act to cleave extracellular peptides, with the resulting oligopeptides and amino acids subsequently transported into the cell and used to supplement auxotrophies and/or ATP production.

\section{HGT in Cand. IA}

The metabolic analysis described above clearly indicates that Cand. IA genome possesses relatively limited metabolic capabilities as compared with free-living archaeal copiotrophs and oligotrophs. Nevertheless, unlike the model obligate archaeal symbionts within the 'Nanoarchaeota' ('Nanoarchaeum equitans' and 'Nanoarchaeota' strain Nst1; Podar et al., 2013), it appears to possess pathways allowing for the independent production of ATP and the biosynthesis of multiple key metabolites. To examine whether the observed metabolic capacities within Cand. IA are because of a reductive evolutionary process of gene loss from a metabolically versatile ancestor, or to gene acquisition by a metabolically limited ancestor, we analyzed the occurrence and prevalence of HGT events within Cand. IA genome. Because of the limited genomes available representing the DPANN superphylum, identification of incidents of HGT from an archaeal donor was not feasible. Therefore, our analysis was limited to the identification of genes having nonarchaeal origins within Cand. IA genome.

Cand. IA genome showed a higher percentage of proteins $(25.4 \%, n=305)$ with apparent bacterial Blastp first hits compared with all other archaeal genomes examined (those ranged from $1.44 \%$ in 'Nanoarchaeum equitans' to $16.9 \%$ in Candidatus Micrarchaeum acidiphilum ARMAN2; Figure 2a). A disproportionately large percentage (116 out of 196) of metabolism-related genes in Cand. IA genome were of apparent bacterial origin, with the majority of these metabolic genes (86 out of 116) involved in biosynthetic pathways (Figure 2b). Maximum likelihood analysis of the phylogenetic affiliation of 21 'Diapherotrites' anabolic proteins confirmed their putative bacterial origin (Supplementary Figure S1). Detailed analysis of the impact of HGT on every metabolic pathway examined is summarized in Table 2 and Supplementary Table S3. Out of 26 metabolic pathways examined, 21 showed evidence of HGT with at least one gene in the pathway with bacterial Blastp first hit. In some cases, an entire metabolic pathway was completely bacterial in origin, for example, biosynthesis of threonine, histidine, arginine and proline. Within other pathways, a fraction of the genes were bacterial in origin; but these genes appear to mediate the critical/defining steps of the pathway, for example, PHB depolymerase in PHB degradation pathway and phosphoenolpyruvate synthase in gluconeogenesis. It is notable that many of the metabolic pathways affected by HGT are absent from 'Nanoarchaeum equitans', the model Nanoarchaeal obligate endosymbiont (Table 2 and Supplementary Table S3). Phylogenetic analysis suggests multiple bacterial phyla as potential gene donors to the Cand. IA genome (Table 2), although within HGT acquired genes, overlapping genes as well as genes with multiple copies usually appear to have the same bacterial donor.

Collectively, the acquired genes enabled Cand. IA to: (1) synthesize alanine, threonine, arginine, proline, histidine and aromatic amino acids, purine and pyrimidine nucleotides and the cofactor pyridoxal phosphate, (2) to convert pterin to folate, (3) to uptake and activate thiamine, (4) to break down proteins extracellularly and potentially uptake the resulting oligopeptides and amino acids and (5) to utilize alanine and valine as possible $\mathrm{C}$ and energy sources, and to depolymerize PHB. These results demonstrate that cross-kingdom HGT events represent an important mechanism that contributes to enhancing the metabolic capacities of Cand. IA. 
Table 2 Metabolic features and potential origins of metabolic genes in Cand. IA genome

\section{Biosynthetic pathways}

A. Pathways entirely bacterial in origin

1. Amino acids

b. Ala from pyruvate

c. Glu from Ala and $\alpha-K G$

d. Thr from Asp (missing 1)

e. His from PRPP

\section{$1 / 1$}

$1 / 1$

$1 / 1$

\section{$4 / 4$}

$8 / 8$

f. Arg from carbamoyl-P and Asp

$6 / 6$

g. Pro from Glu

Armatimonadetes, and CD JS-1

Firmicutes, Thermotoga, Proteobacteria, and Deferribacter

Deferribacter $\quad 0 / 1$

Thermodesulfobacteria $\quad 0 / 1$

Thermodesulfobacteria $\quad 0 / 1$

Bacteroidetes, Acidobacteria, Spirochaetes $\quad 0 / 4$

Acidobacteria, Synergistetes, Proteobacteria, $\quad$ 2/9

Firmicutes, Aminicenantes, and Parcubacteria

Thermotoga, Firmicutes, Spirochaetes, Bacteroidetes $\quad 1 / 6$

and Cyanobacteria

Firmicutes and Aquificae

B. Pathways partially bacterial in origin

1. Amino acids

a. Asn from Asp

b. Aromatic amino acids from 7-phospho-

2/5 Firmicutes and Aquificae

2-dehydro-3-deoxy-D-arabino-heptonate

i. $\operatorname{Trp}$

$8 / 12$

Proteobacteria, Therodesulfobacteria, Planctomycetes,

iii. Tyr

2. Cofactors
a. Thiamine
b. Riboflavin
c. Nicotinate and nicotinamide
d. Pantothenate and CoA

\section{Nucleotides \\ a. Purine from ribose-1-P \\ b. Pyrimidine from glutamine and PRPP}

Planctomycetes, Proteobacteria, Firmicutes, Lentisphaera, and Omnitrophica

Bacteroidetes, Proteobacteria, Cyanobacteria, Firmicutes,

Planctomycetes, and Omnitrophica

\section{Carbohydrates}

Gluconeogenesis to fructose-6-P

C. Pathways entirely archaeal in origin

a. Ser from 3-P glycerate

b. Gln from Glu

$0 / 3 \quad$ NA

$0 / 6 \quad$ NA

$0 / 1 \quad$ NA

II. Catabolic pathways (partially bacterial in origin)

1. PHB degradation

2. Ribose degradation

3. Peptidases

4. Potential ETS
Actinobacteria and Proteobacteria

Thermodesulfobacteria, Acidobacteria, Firmicutes,

Bacteroidetes, and Parcubacteria

Actinobacteria and Firmicutes

Proteobacteria and Firmicutes
$1 / 5$

$5 / 12$

Abbreviations: Cand. IA, Candidatus 'Iainarchaeum andersonii'; HGT, horizontal gene transfer; PHB, polyhydroxybutyrate; PRPP, 5-phospho- $\alpha$-Dribosyl 1-pyrophosphate.

aNumber of HGT candidates/total number of genes in the pathway.

bNumber of genes/total number of genes in the pathway with homologs in the published Nanoarchaeal genomes.

Genome architecture and COG distribution patterns in Cand. IA genome

Various genomic features and COG distribution patterns in microbial genomes have successfully been correlated to putative trophic lifestyles, for example, oligotrophy, copiotrophy (Giovannoni et al., 2005; Lauro et al., 2009; Swan et al., 2013) as well as obligate symbiosis (Moran and Wernegreen, 2000; Shigenobu et al., 2000; Akman et al., 2002; Tamas et al., 2002; Moran et al., 2003; 
454

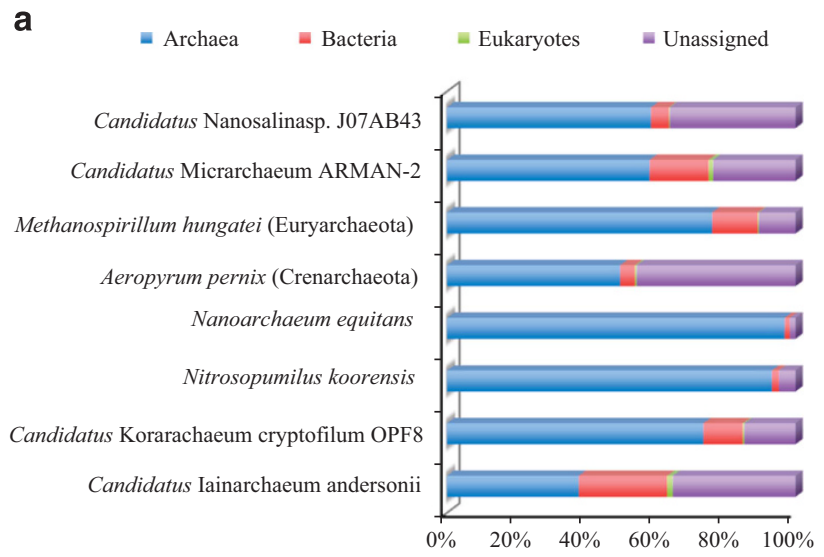

b

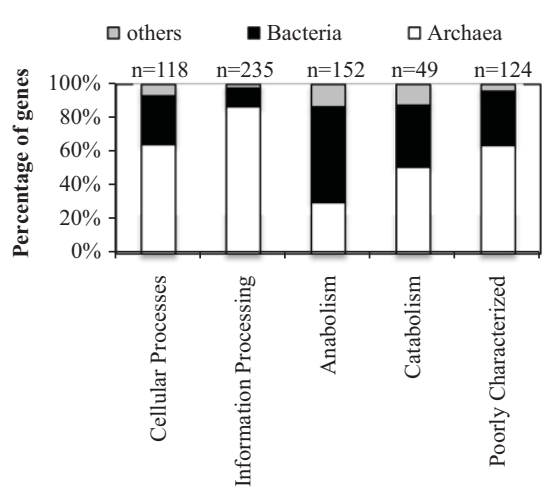

Figure 2 (a) Phylogenetic distribution of non-self Blastp first hits of Candidatus Iainarchaeum andersonii proteins compared with other archaeal phyla representatives. (b) Phylogenetic distribution at the domain level of non-self Blastp first hits of Candidatus Iainarchaeum andersonii proteins classified by metabolic category in the $\mathrm{X}$ axis. Total number of proteins belonging to each category are shown above each column.

Waters et al., 2003; Moya et al., 2008; Nikoh et al., 2011; Hendry et al., 2013; Podar et al., 2013). In an effort to decipher the putative trophic lifestyle of Cand. IA, we used PCA to compare Cand. IA genome with those of 19 other archaeal genomes (Supplementary Table S2) encompassing obligate oligotrophs, obligate archaeal symbionts, fast-growing copiotrophs as well as the slow-growing archaeal copiotrophs (marine groups MCG and Thermoplasmatales MBG-D group thriving in C-rich ocean sediments). PCA biplot (Figure 3) showed that, in general, genomes clustered according to their trophic lifestyle into four major groups: fastgrowing copiotrophs, slow-growing copitrophs, obligate oligotrophs and obligate symbionts, with the later being highly divergent and clustering away from other genomes. This was expected as archaeal symbionts exhibit a dramatic reduction in metabolism-related and an expansion in information processing-related gene families (Waters et al., 2003; Podar et al., 2013).

Cand. IA genome did not cluster with any of the above groups in the PCA biplot, but rather showed a distinct position between the obligate nanoarchaeal symbionts and the archaeal oligotrophs.
This position is a reflection of the overrepresentation of replication-related, post-translational modification-related and nucleotide metabolism-related proteins compared with other genomes, as well as the overrepresentation of translation-related proteins compared with all other genomes with the exception of 'Nanoarchaeota'. The position of Cand. IA in the same quadrant with archaeal symbionts and oligotrophs is a reflection of the shared streamlining genomic characteristics, for example, smaller genome size and significantly lower percentage of cell membrane proteins, when compared with copiotrophs. However, salient differences exist between Cand. IA and typical oligotrophs and obligate symbionts. Compared with 'Nitrosopumilis maritimus' genome (a model archaeal oligotroph), Cand. IA genome has an overrepresentation of replication, translation, transcription, nucleotide metabolism, intracellular trafficking and secretion and cell wall biogenesis COGs as well as proteins destined to the cell wall, and an underrepresentation of signal transduction, defense mechanisms, energy, amino acid, coenzyme, inorganic ion and secondary metabolism COGs as well as transporters and extracellular proteins (Figure 3 and Supplementary Table S2). Similarly, compared with 'Nanoarchaeum equitans' genome (a model archaeal obligate symbiont), Cand. IA genome has a larger genome, an overrepresentation of energy, amino acid, nucleotide, carbohydrate, coenzyme, lipid and inorganic ion metabolism, cell wall biogenesis and signal transduction COGs, and an underrepresentation of translation, replication and post-translational modification COGs. Interestingly, many of these defining features between archaeal symbionts and Cand. IA could be mediated by the acquisition of genes via HGT as described above. The disparate position of all DPANN genomes analyzed is striking, and underscores the high level of diversity in genomic architecture, metabolic potential and trophic lifestyle within the DPANN superphylum (Rinke et al., 2013).

\section{Global distribution of the 'Diapherotrites'}

The 16S rRNA genes obtained from the three available 'Diapherotrites' SAG genome assemblies were shorter (average length is $1312 \mathrm{bp}$ ) than other archaeal counterparts, mainly because of the absence of bases corresponding to 1-20 and 1381-1540 in Methanobacterium formimicum (Gutell et al., 1985). Therefore, universal 16S rRNA gene primers targeting these regions (for example, A1F, U1406R and U1510R) (Baker et al., 2003) would theoretically fail to identify 'Diapherotrites' members. Furthermore, within these shortened 16S rRNA genes, mismatches to almost all known archaeal-specific or universal 16S rRNA gene primers were identified in all three available 'Diapherotrites' SAG genome assemblies, with the exception of $109 \mathrm{~F}, 515 \mathrm{~F}$ and $534 \mathrm{R}$ (Table 3). 


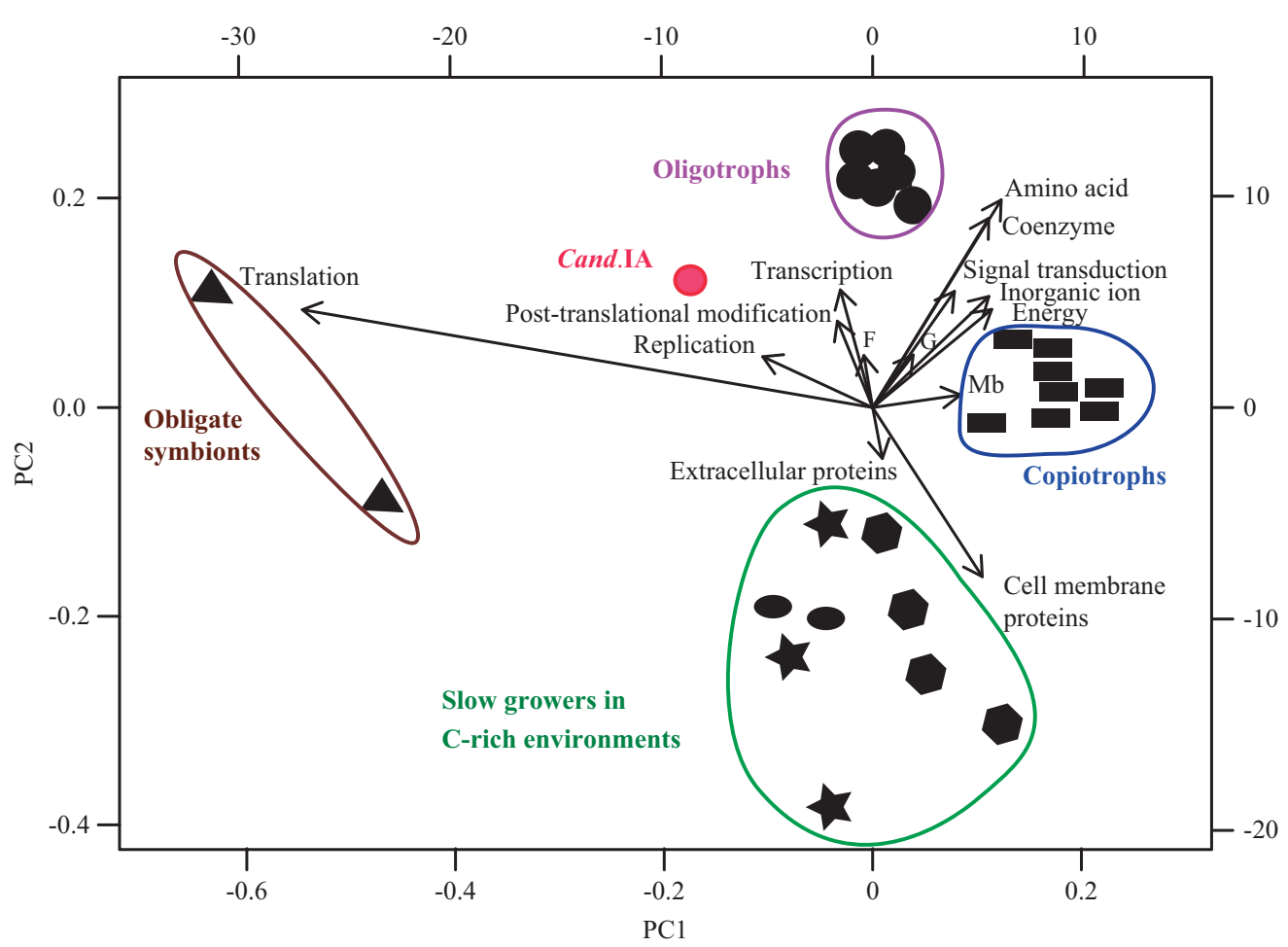

Figure 3 PCA biplot of the genomic features and COG category distribution in the genomes compared. Genomes are represented by symbols according to their trophic lifestyle. A list of genomes, as well as features used in this analysis, and trophic lifestyles are presented in Supplementary Table S2. Arrows represent genomic features or COG categories used for comparison. The arrow directions follow the maximal abundance, and their lengths are proportional to the maximal rate of change between genomes. The first two components explained $75 \%$ of variation. Obligate oligotrophs of the Thaumarchaeota (depicted by circles) clustered together because of abundance of amino acid, nucleotide and coenzyme metabolism-related as well as post-translational modification and transcriptionrelated proteins, the copiotrophs (depicted by rectangles) clustered together mainly because of their large genome sizes and a higher percentage of membrane proteins relative to other groups, and the slow-growing copiotrophs of the Thermoplasmatales (depicted by hexagons) clustered together because of the expansion of membrane as well as extracellular proteins consistent with previous reports of a higher percentage of membrane transporters and extracellular peptidases in those genomes (Lloyd et al., 2013). Parvarchaeota genomes (depicted by stars) and Nanohaloarchaeota genomes (depicted by ovals) also clustered close to the slow-growing copiotrophs. Finally, the two obligate symbionts of Nanoarchaeota (depicted by triangles) clustered together away from all other genomes mainly because of expansion of translation-related proteins. Candidatus Iainarchaeum andersonii genome is represented by a red circle and has an intermediate position in the plot. F, COG category nucleotide metabolism; G, COG category carbohydrate metabolism; Mb, genome size.

With mismatches to known primers, 'Diapherotrites' sequences would theoretically be missed in cultivation-independent PCR-based surveys. Indeed, comparison of 'Diapherotrites' to Sanger-generated, near-full-length 16S rRNA genes deposited in GenBank nr database failed to identify any 'Diapherotrites'-related 16S rRNA gene sequences. In addition, within a 16S rRNA data set generated using primer pair $926 \mathrm{wF}$ and $1392 \mathrm{R}$ from the same sample from which the three 'Diapherotrites' SAGs were obtained, no 'Diapherotrites' 16S rRNA gene sequences were amplified (Supplementary Table S4). Furthermore, within a collection of 31972882 archaeal next-generation sequences spanning 58 habitats and 775 data sets, only 66 sequences were confidently assigned to the 'Diapherotrites' phylum from 3 different studies, where they were identified in a paddy soil (Feng et al., 2013), three distinct soils (Portillo et al., 2013) and wastewater treatment plant (Vishnivetskaya et al., 2013).

Finally, we used phylogenetic anchoring to identify the presence of members of the 'Diapherotrites' in publicly available metagenomic data sets $(n=893)$. The 'Diapherotrites' were only identified in a handful of environments (11 out of 893 analyzed). These include Amazon forest soil, mangrove sediment on Isabella Island, Sakinaw lake, Etoliko lagoon sediment and Kolumbo Volcano red mat (Supplementary Figure S2). Within these studies, the 'Diapherotrites' were always identified as an extremely minor fraction of the community $(<0.006 \%$ of anchored metagenomic reads).

\section{Discussion}

In this study, we present a detailed analysis of the metabolic capabilities and genomic features of three SAGs belonging to the recently proposed archaeal phylum 'Diapherotrites', as well as a survey of the putative distribution of members of this phylum using database-mining approaches. Our detailed genomic analysis of 'Diapherotrites' SAG Cand. IA uncovers evidence for genome streamlining: 
Table 3 Mismatches of 'Diapherotrites' 16S rRNA gene to universal archaeal primers ${ }^{\mathrm{a}}$

\begin{tabular}{|c|c|c|}
\hline Primer name & Primer sequence $\left(5^{\prime}-3^{\prime}\right)$ & Sequence in Diapherotrites $\left(5^{\prime}-3^{\prime}\right)$ \\
\hline A109F & ACKGCTCAGTAACACGT & ACKGCTCAGTAACACGT \\
\hline A333F & TCCAGGCCCTACGGG & CCCTAGCCCTAMGGG \\
\hline $\mathrm{AB} 341 \mathrm{~F}$ & CCTACGGGRSGCAGCAG & CCTAMGGGRTGCAGCAG \\
\hline A344F & ACGGGGTGCAGCAGGCGCGA & AMGGGGTGCAGCAGKYRSGA \\
\hline U515F & GTGCCAGCMGCCGCGGTAA & GTGCCAGCMGCCGCGGTAA \\
\hline U519F & CAGCMGCCGCGGTAATWC & CAGCMGCCGCGGTAATWC \\
\hline UA571F & GCYTAAAGSRICCGTAGC & GCYTAAAGSRIYYGTAGC \\
\hline UA751F & CCGACGGTGAGRGRYGAA & CTGACGGTGAGRRRYGAA \\
\hline $\mathrm{AB} 779 \mathrm{~F}$ & GCRAASSGGATTAGATACCC & GCRACSSGGATTAGATACCC \\
\hline EB787F & ATTAGATACCCTGGTA & ATTAGATACCCGGTTA \\
\hline AB787F & ATTAGATACCCGGGTA & ATTAGATACCCGGTTA \\
\hline Ab789F & TAGATACCCSSGTAGTCC & TAGATACCCSSTTAGTCC \\
\hline AB906F & GAAACTTAAAKGAATTG & GAAACTTAAWKGAATTG \\
\hline A1040F & GAGAGGWGGTGCATGGCC & GAGAGGWGYTGTATGGYC \\
\hline U1053F & GCATGGCYGYCGTCAG & GTATGGCYAYYKKCAG \\
\hline A1098F & GGCAACGAGCGMGACCC & GGCAACGGGCGMGACCY \\
\hline AB127R & CCACGTGTTACTSAGC & CBACGTGTTACTSAGC \\
\hline A348R & CCCCGTAGGGCCYGG & CCCCKTAGGGCTAGG \\
\hline U534R & GWATTACCGCGGCKGCTG & GTATTACCGCGGCGGCTG \\
\hline U529R & ACCGCGGCKGCTGGC & ACCGCGGCGGCTGGC \\
\hline AB909R & TTTCAGYCTTGCGRCCGTAC & TTTCACYCTTGCGRGYRTAC \\
\hline A927R & CCCGCCAATTCCTTTAAGTTTC & CCCGCCAATTCCWTTAAGTTTC \\
\hline A926R & CCGTCAATTCCTTTRAGTTT & CCGCCAATTCCWTTRAGTTT \\
\hline A934R & GTGCTCCCCCGCCAATTCCT & GTGMGCYCCCGCCAATTCCW \\
\hline A976R & YCCGGCGTTGAMTCCAATT & YCYGGCGTTGTRTCCRATT \\
\hline A1115R & GGGTCTCGCTCGTTG & RGGTCTCGCYCGTTG \\
\hline UA1204R & TTMGGGGCATRCIKACCT & TTMGGGCYATRCIKAYCT \\
\hline
\end{tabular}

Mismatches in 'Diapherotrites' sequences are shown in bold.

${ }^{a}$ Using the $16 \mathrm{~S}$ rRNA gene sequences of the three Diapherotrites single amplified genomes (SAGs).

prevalence of HGT events, especially in metabolismrelated genes; limited catabolic capabilities with only few substrates that could potentially be utilized for ATP production; and a limited representation of members of this phylum in amplicon-generated and metagenomic data sets.

Many of the genomic streamlining features observed in Cand. IA genome, such as small genome size, small intergenic regions, low incidences of gene duplication and low number of rRNA operons, have been associated with specific trophic lifestyles, mainly oligotrophy and obligate symbiosis (Giovannoni et al., 2005; Lauro et al., 2009; Walker et al., 2010; Grote et al., 2012; Swan et al., 2013), where they appear to be a reflection of the accessibility of nutrients, as well as the occurrence of genetic drift in obligate symbionts (Mira et al., 2001; Wernegreen, 2002; Giovannoni et al., 2005; Oakeson et al., 2014). However, detailed comparative analysis of the metabolism and genomic features of Cand. IA revealed salient differences when compared with the genomes of model archaeal obligate symbionts and oligotrophs.

Compared with the genome of the model archaeal obligate symbiont 'Nanoarchaeum equitans', Cand. IA genome possesses multiple catabolic abilities that allow for the production of ATP from few substrates (valine, alanine, aspartate, ribose and PHB) (Figure 1, Table 2, and Supplementary Text). Such capabilities are completely absent from 'N. equitans' genome (Waters et al., 2003).
More importantly, Cand. IA possesses an anabolic machinery that allows for the biosynthesis of multiple amino acids, nucleotides and cofactors (Figure 1, Table 2 and Supplementary Text); a feature that is absent in ' $N$. equitans' because of its dependence on its host for supplying such metabolites (Waters et al., 2003).

In contrast to archaeal oligotrophs that have numerous transport capabilities, a well-developed essential biosynthetic machinery as well as complete central metabolic pathways (Walker et al., 2010; Nunoura et al., 2011), Cand. IA exhibits lower transport capabilities (Supplementary Table S2), higher level of auxotrophy and incomplete and/or less developed pathways (for example, respiratory chain, tricarboxylic acid cycle and pentose phosphate pathway). Furthermore, the catabolic capabilities of Cand. IA appear to be geared toward utilizing substrates that are more common in nonoligotrophic habitats. For example, ribose, being a lysis product of RNA, is presumably more available in non-oligotrophic environments characterized by higher rates of cell turnover and lysis. Indeed, both the transporters and the carbohydrate utilization patterns of the SAR11 clade comprising the oligotrophic ocean bacteria suggest the inability to takeup and utilize carbohydrates (including ribose) as a carbon and energy source (Jiao and Zheng, 2011). Similarly, PHBs are storage molecules produced by several bacterial species in response to either an excess of carbon or a limitation of another nutrient, 
for example, nitrogen or phosphorous (Jendrossek and Handrick, 2002), and hence would be expected to exist in C-rich environments (Jendrossek and Handrick, 2002).

Analysis of the global ecological distribution of members of the 'Diapherotrites' identified its presence in only a few environments (Supplementary Figure S2). However, this observed pattern of paucity of 'Diapherotrites' sequences in either amplicon-generated or metagenomic data sets could be influenced by the mismatches identified to the most commonly utilized 16S rRNA gene primers (Table 3), or the limited number of 'Diapherotrites' reference sequences available to serve as substrates for phylogenetic anchoring analysis, respectively. Nevertheless, examination of the origin and trophic status of habitats where the 'Diapherotrites' were identified suggest their preference to nonoligotrophic environments (for example, microbial mats, high productivity forests, wastewater treatment plants (Vishnivetskaya et al., 2013) and soils (Feng et al., 2013; Portillo et al., 2013)).

We argue that the observed metabolic capacities, genomic features and ecological distribution as well as the observed high proportion of genes involved in cross-kingdom HGT (Table 2 and Supplementary Table S3) could be explained by a conceptual model where gene acquisition plays an important role in shaping the evolutionary history of Cand. IA. Specifically, we argue that this acquisition process is mediating the putative transition of Cand. IA from a symbiotic ancestor with a streamlined genome and extremely limited metabolic capabilities to a free-living microorganism, capable of ATP production (although from a limited number of substrates), as well as biosynthesis of multiple amino acids, nucleotides and cofactors, although it remains auxotrophic to other several cellular building blocks. Indeed, most of the key differences in genome architecture between ' $N$. equitans' and Cand. IA (Figure 3) could be brought about by the presence of additional genes of apparent bacterial origin in the genome assembly. Theoretically, removal of genes of bacterial origin from the Cand. IA genome would produce a genome assembly with features and metabolic capacities very similar to the genome ' $N$. equitans' (Supplementary Figure S3).

Although the role of HGT in conferring specific capabilities to recipient prokaryotic species, for example, antibiotic resistance or heavy metal resistance (Andam et al., 2011; Navarro et al., 2013), has long been recognized, the impact of HGT on prokaryotic evolutionary history and its potential role in organismal transition to new habitats and lifestyles has received less attention. The acquisition of bacterial genes was recently proposed as a driver of Halobacteriales evolution from a methanogenic ancestor (Nelson-Sathi et al., 2012). Within the eukaryotes, HGT has been shown to be important in the development of thermoacidophily and subsequent adaptation of the red algae Galdieria sulphuraria to hot acidic habitats (Qiu et al., 2013; Schönknecht et al., 2013), as well as the adaptation of gut fungi (Neocallimastigomycota) to the strict anaerobic, eutrophic and plant biomass-rich habitat in the herbivorous gut (Youssef et al., 2013). Additional research to provide a more detailed understanding of the impact of such processes on microbial (especially prokaryotic) evolution is certainly warranted.

\section{Conflict of Interest}

The authors declare no conflict of interest.

\section{Acknowledgements}

This work was supported by the National Science Foundation Microbial Observatories Program (Grant EF0801858).

\section{References}

Akman L, Yamashita A, Watanabe H, Oshima K, Shiba T, Hattori $M$ et al. (2002). Genome sequence of the endocellular obligate symbiont of tsetse flies, Wigglesworthia glossinidia. Nat Genet 32: 402-407.

Altschul SF, Gish W, Miller W, Myers EW, Lipman DJ. (1990). Basic local alignment search tool. J Mol Biol 215: 403-410.

Andam CP, Fournier GP, Gogarten JP. (2011). Multilevel populations and the evolution of antibiotic resistance through horizontal gene transfer. FEMS Microbiol Rev 35: 756-767.

Antoine E, Guezennec J, Meunier JR, Lesongeur F, Barbier G. (1995). Isolation and characterization of extremely thermophilic archaebacteria related to the genus Thermococcus from deep-sea hydrothermal guaymas basin. Curr Microbiol 31: 186-192.

Aono R, Sato T, Yano A, Yoshida S, Nishitani Y, Miki K et al. (2012). Enzymatic characterization of AMP phosphorylase and ribose-1,5-bisphosphate isomerase functioning in an Archaeal AMP metabolic pathway. J Bacteriol 194: 6847-6855.

Baker BJ, Banfield JF. (2003). Microbial communities in acid mine drainage. FEMS Microbiol Ecol 44: $139-152$

Baker BJ, Comolli LR, Dick GJ, Hauser LJ, Hyatt D, Dill BD et al. (2010). Enigmatic, ultrasmall, uncultivated Archaea. Proc Natl Acad Sci USA 107: 8806-8811.

Baker GC, Smith JJ, Cowan DA. (2003). Review and re-analysis of domain-specific $16 \mathrm{~S}$ primers. J Microbiol Meth 55: 541-555.

Bates ST, Berg-Lyons D, Caporaso JG, Walters WA, Knight R, Fierer N. (2011). Examining the global distribution of dominant archaeal populations in soil. ISME J 5: 908-917.

Benlloch S, Acinas SG, Antón J, López-López A, Luz SP, Rodríguez-Valera F. (2001). Archaeal biodiversity in crystallizer ponds from a solar Saltern: culture versus PCR. Microb Ecol 41: 12-19.

Benlloch S, Lopez-Lopez A, Casamayor EO, Ovreas L, Goddard V, Daae FL et al. (2002). Prokaryotic genetic diversity throughout the salinity gradient of a coastal solar saltern. Environ Microbiol 4: 349-360. 
Berdjeb L, Pollet T, Chardon C, Jacquet S. (2013). Spatio-temporal changes in the structure of archaeal communities in two deep freshwater lakes. FEMS Microbiol Ecol 86: 215-230.

Bintrim SB, Donohue TJ, Handelsman J, Roberts GP, Goodman RM. (1997). Molecular phylogeny of Archaea from soil. Proc Natl Acad Sci USA 94: 277-282.

Bond PL, Smriga SP, Banfield JF. (2000). Phylogeny of microorganisms populating a thick, subaerial, predominantly lithotrophic biofilm at an extreme acid mine drainage site. Appl Environ Microbiol 66: 3842-3849.

Bricheux G, Morin L, Le Moal G, Coffe G, Balestrino D, Charbonnel $\mathrm{N}$ et al. (2013). Pyrosequencing assessment of prokaryotic and eukaryotic diversity in biofilm communities from a French river. Microbiol Open 2: 402-414.

Brochier-Armanet C, Boussau B, Gribaldo S, Forterre P. (2008). Mesophilic crenarchaeota: proposal for a third archaeal phylum, the Thaumarchaeota. Nat Rev Micro 6: $245-252$.

Cui H-L, Gao X, Sun F-F, Dong Y, Xu X-W, Zhou Y-G et al. (2010). Halogranum rubrum gen. nov., sp. nov., a halophilic archaeon isolated from a marine solar saltern. Int J Syst Evol Microbiol 60: 1366-1371.

DeLong EF. (1992). Archaea in coastal marine environments. Proc Natl Acad Sci USA 89: 5685-5689.

Dick G, Andersson A, Baker B, Simmons S, Thomas B, Yelton AP et al. (2009). Community-wide analysis of microbial genome sequence signatures. Genome Biol 10: R85.

Dopson M, Baker-Austin C, Hind A, Bowman JP, Bond PL. (2004). Characterization of Ferroplasma Isolates and Ferroplasma acidarmanus sp. nov., extreme acidophiles from acid mine drainage and industrial bioleaching environments. Appl Environ Microbiol 70: 2079-2088.

Edwards KJ, Bond PL, Gihring TM, Banfield JF. (2000). An Archaeal iron-oxidizing extreme acidophile important in acid mine drainage. Science 287: 1796-1799.

Elkins JG, Podar M, Graham DE, Makarova KS, Wolf Y, Randau L et al. (2008). A Korarchaeal genome reveals insights into the evolution of the Archaea. Proc Natl Acad Sci USA 105: 8102-8107.

Farag IF, Davis JP, Youssef NH, Elshahed MS. (2014). Global patterns of abundance, diversity and community structure of the Aminicenantes (candidate phylum OP8). PLoS One 9: e92139.

Feng Y, Lin X, Yu Y, Zhang H, Chu H, Zhu J. (2013). Elevated ground-level $\mathrm{O}_{3}$ negatively influences paddy methanogenic archaeal community. Sci Rep 3: 3193.

Fuhrman JA, McCallum K, Davis AA. (1992). Novel major archaebacterial group from marine plankton. Nature 356: 148-149.

Ghai R, Pašić L, Fernández AB, Martin-Cuadrado A-B, Mizuno CM, McMahon KD et al. (2011). New abundant microbial groups in aquatic hypersaline environments. Sci Rep 1: 135.

Giovannoni SJ, Tripp HJ, Givan S, Podar M, Vergin KL, Baptista D et al. (2005). Genome streamlining in a cosmopolitan oceanic bacterium. Science 309: 1242-1245.

Goh F, Jeon YJ, Barrow K, Neilan BA, Burns BP. (2011). Osmoadaptive strategies of the archaeon Halococcus hamelinensis Isolated from a hypersaline stromatolite environment. Astrobiology 11: 529-536.
Grote J, Thrash JC, Huggett MJ, Landry ZC, Carini P, Giovannoni SJ et al. (2012). Streamlining and core genome conservation among highly divergent members of the SAR11 clade. mBio 3: e00252-12.

Gutell RR, Weiser B, Woese CR, Noller HF. (1985). Comparative anatomy of 16-S-like ribosomal RNA. Prog Nucleic Acid Res Mol Biol 32: 155-216.

Guy L, Ettema TJ. (2011). The archaeal 'TACK' superphylum and the origin of eukaryotes. Trends Microbiol 19: $580-587$.

Hallam SJ, Putnam N, Preston CM, Detter JC, Rokhsar D, Richardson PM et al. (2004). Reverse methanogenesis: testing the hypothesis with environmental genomics. Science 305: 1457-1462.

Hendry TA, de Wet JR, Dunlap PV. (2013). Genomic signatures of obligate host dependence in the luminous bacterial symbiont of a vertebrate. Environ Microbiol; e-pub ahead of print 10 October 2013; doi:10.1111/1462-2920.12302.

$\mathrm{Hu}$ A, Jiao N, Zhang R, Yang Z. (2011). Niche partitioning of marine group I Crenarchaeota in the euphotic and upper mesopelagic zones of the East China Sea. Appl Environ Microbiol 77: 7469-7478.

Huber G, Spinnler C, Gambacorta A, Stetter KO. (1989). Metallosphaera sedula gen, and sp. nov. Represents a new genus of aerobic, metal-mobilizing, thermoacidophilic Archaebacteria. Syst Appl Microbiol 12: 38-47.

Huber G, Huber R, Jones BE, Lauerer G, Neuner A, Segerer A et al. (1991). Hyperthermophilic archaea and bacteria occurring within Indonesian hydrothermal areas. Syst Appl Microbiol 14: 397-404.

Inoue K, Itoh T, Ohkuma M, Kogure K. (2011). Halomarina oriensis gen. nov., sp. nov., a halophilic archaeon isolated from a seawater aquarium. Int J Syst Evol Microbiol 61: 942-846.

Itoh T, Suzuki K-i, Sanchez PC, Nakase T. (1999). Caldivirga maquilingensis gen. nov., sp. nov., a new genus of rod-shaped crenarchaeote isolated from a hot spring in the Philippines. Int J Syst Bacteriol 49: 1157-1163.

Jannasch HW, Wirsen CO, Molyneaux SJ, Langworthy TA. (1992). Comparative physiological studies on hyperthermophilic Archaea isolated from deep-sea hot vents with emphasis on Pyrococcus strain GB-D. Appl Environ Microbiol 58: 3472-3481.

Jendrossek D, Handrick R. (2002). Microbial degradation of polyhydroxyalkanoates. Annu Rev Microbiol 56: 403-432.

Jiao N, Zheng Q. (2011). The microbial carbon pump: from genes to ecosystems. Appl Environ Microbiol 77: 7439-7444.

Kanehisa M. (2002). The KEGG database. Novartis Found Symp 247: 91-101. discussion 101-103, 119-128, 244-152.

Karner MB, DeLong EF, Karl DM. (2001). Archaeal dominance in the mesopelagic zone of the Pacific Ocean. Nature 409: 507-510.

Karp PD, Riley M, Paley SM, Pellegrini-Toole A. (2002). The MetaCyc Database. Nucleic Acids Res 30: 59-61.

Konneke M, Bernhard AE, de la Torre JR, Walker CB, Waterbury JB, Stahl DA. (2005). Isolation of an autotrophic ammonia-oxidizing marine archaeon. Nature 437: 543-546.

Lake JA, Henderson E, Oakes M, Clark MW. (1984). Eocytes: a new ribosome structure indicates a 
kingdom with a close relationship to eukaryotes. Proc Natl Acad Sci USA 81: 3786-3790.

Larkin MA, Blackshields G, Brown NP, Chenna R, McGettigan PA, McWilliam $\mathrm{H}$ et al. (2007). Clustal W and Clustal $\mathrm{X}$ version 2.0. Bioinformatics 23: 2947-2948.

Lauro FM, McDougald D, Thomas T, Williams TJ, Egan S, Rice $S$ et al. (2009). The genomic basis of trophic strategy in marine bacteria. Proc Natl Acad Sci USA 106: 15527-15533.

Leinonen R, Sugawara H, Shumway M. (2011). The sequence read archive. Nucleic Acids Res 39: D19-D21.

Lin X, McKinley J, Resch CT, Kaluzny R, Lauber CL, Fredrickson J et al. (2012). Spatial and temporal dynamics of the microbial community in the Hanford unconfined aquifer. ISME J 6: 1665-1676.

Lloyd KG, Schreiber L, Petersen DG, Kjeldsen KU, Lever MA, Steen AD et al. (2013). Predominant archaea in marine sediments degrade detrital proteins. Nature 496: 215-218.

Marchler-Bauer A, Lu S, Anderson JB, Chitsaz F, Derbyshire MK, DeWeese-Scott C et al. (2010). CDD: a conserved domain database for the functional annotation of proteins. Nucleic Acids Res 39: D225-D229.

Massana R, Murray AE, Preston CM, DeLong EF. (1997). Vertical distribution and phylogenetic characterization of marine planktonic Archaea in the Santa Barbara Channel. Appl Environ Microbiol 63: 50-56.

McLean JS, Lombardo M-J, Badger JH, Edlund A, Novotny M, Yee-Greenbaum J et al. (2013). Candidate phylum TM6 genome recovered from a hospital sink biofilm provides genomic insights into this uncultivated phylum. Proc Natl Acad Sci USA 110: E2390-E2399.

Meyer F, Paarmann D, D’Souza M, Olson R, Glass EM, Kubal $\mathrm{M}$ et al. (2008). The metagenomics RAST server - a public resource for the automatic phylogenetic and functional analysis of metagenomes. $B M C$ Bioinfomatics 9: 386.

Mikucki JA, Liu Y, Delwiche M, Colwell FS, Boone DR. (2003). Isolation of a methanogen from deep marine sediments that contain methane hydrates, and description of Methanoculleus submarinus sp. nov. Appl Environ Microbiol 69: 3311-3316.

Minegishi H, Mizuki T, Echigo A, Fukushima T, Kamekura M, Usami R. (2008). Acidophilic haloarchaeal strains are isolated from various solar salts. Saline Systems 4: 16.

Minegishi H, Yamauchi Y, Echigo A, Shimane Y, Kamekura M, Itoh $\mathrm{T}$ et al. (2013). Halarchaeum nitratireducens sp. nov., a moderately acidophilic haloarchaeon isolated from commercial sea salt. Int J Syst Evol Microbiol 63: 4202-4206.

Mira A, Ochman H, Moran NA. (2001). Deletional bias and the evolution of bacterial genomes. Trends Genet 17: 589-596.

Moran NA, Wernegreen JJ. (2000). Lifestyle evolution in symbiotic bacteria: insights from genomics. Trends Ecol Evol 15: 321-326.

Moran NA, Plague GR, Sandstrom JP, Wilcox JL. (2003). A genomic perspective on nutrient provisioning by bacterial symbionts of insects. Proc Natl Acad Sci USA 100: 14543-14548.

Moya A, Pereto J, Gil R, Latorre A. (2008). Learning how to live together: genomic insights into prokaryote-animal symbioses. Nat Rev Genet 9: 218-229.
Narasingarao P, Podell S, Ugalde JA, Brochier-Armanet C, Emerson JB, Brocks JJ et al. (2012). De novo metagenomic assembly reveals abundant novel major lineage of Archaea in hypersaline microbial communities. ISME J 6: 81-93.

Navarro CA, von Bernath D, Jerez CA. (2013). Heavy metal resistance strategies of acidophilic bacteria and their acquisition: importance for biomining and bioremediation. Biol Res 46: 363-371.

Nelson-Sathi S, Dagan T, Landan G, Janssen A, Steel M, McInerney JO et al. (2012). Acquisition of 1,000 eubacterial genes physiologically transformed a methanogen at the origin of Haloarchaea. Proc Natl Acad Sci USA 109: 20537-20542.

Nikoh N, Hosokawa T, Oshima K, Hattori M, Fukatsu T. (2011). Reductive evolution of bacterial genome in insect gut environment. Genome Biol Evol 3: 702-714.

Nunoura T, Takaki Y, Kakuta J, Nishi S, Sugahara J, Kazama $\mathrm{H}$ et al. (2011). Insights into the evolution of Archaea and eukaryotic protein modifier systems revealed by the genome of a novel archaeal group. Nucleic Acids Res 39: 3204-3223.

Oakeson KF, Gil R, Clayton AL, Dunn DM, von Niederhausern AC, Hamil C et al. (2014). Genome degeneration and adaptation in a nascent stage of symbiosis. Genome Biol Evol 6: 76-93.

Oren A, Ginzburg M, Ginzburg BZ, Hochstein LI, Volcani BE. (1990). Haloarcula marismortui (Volcani) sp. nov., nom. rev., an extremely halophilic bacterium from the Dead sea. Int J Syst Bacteriol 40: 209-210.

Orphan VJ, Taylor LT, Hafenbradl D, Delong EF. (2000). Culture-dependent and culture-independent characterization of microbial assemblages associated with high-temperature petroleum reservoirs. Appl Environ Microbiol 66: 700-711.

Papadopoulos JS, Agarwala R. (2007). COBALT: constraint-based alignment tool for multiple protein sequences. Bioinformatics 23: 1073-1079.

Podar M, Makarova K, Graham D, Wolf Y, Koonin E, Reysenbach A-L. (2013). Insights into archaeal evolution and symbiosis from the genomes of a nanoarchaeon and its inferred crenarchaeal host from Obsidian Pool, Yellowstone National Park. Biol Direct 8: 9.

Portillo MC, Leff JW, Lauber CL, Fierer N. (2013). Cell size distributions of soil bacterial and archaeal taxa. Appl Environ Microbiol 79: 7610-7617.

Qiu H, Price DC, Weber APM, Reeb V, Chan Yang E, Lee JM et al. (2013). Adaptation through horizontal gene transfer in the cryptoendolithic red alga Galdieria phlegrea. Curr Biol 23: R865-R866.

$\mathrm{R}$ Development Core Team (2008). $R$ : A Language and Environment for Statistical Computing. R Foundation for Statistical Computing: Vienna, Austria.

Rawlings ND, Barrett AJ, Bateman A. (2014). MEROPS: the database of proteolytic enzymes, their substrates and inhibitors. Nucleic Acids Res 42: D503-D509.

Rinke C, Schwientek P, Sczyrba A, Ivanova NN, Anderson IJ, Cheng J-F et al. (2013). Insights into the phylogeny and coding potential of microbial dark matter. Nature 499: 431-437.

Roberts DW. (2012). labdsv: Ordination and Multivariate Analysis for Ecology, R package version 1.5-0. http:// cran.r-project.org/web/packages/labdsv/.

Saier MH, Reddy VS, Tamang DG, Västermark A. (2014). The transporter classification database. Nucleic Acids Res 42: D251-D258. 
Sakai S, Imachi H, Sekiguchi Y, Ohashi A, Harada H, Kamagata Y. (2007). Isolation of key methanogens for global methane emission from rice paddy fields: a novel isolate affiliated with the clone cluster rice cluster I. Appl Environ Microbiol 73: 4326-4331.

Schönknecht G, Chen W-H, Ternes CM, Barbier GG, Shrestha RP, Stanke M et al. (2013). Gene transfer from Bacteria and Archaea facilitated evolution of an extremophilic eukaryote. Science 339: 1207-1210.

Shigenobu S, Watanabe H, Hattori M, Sakaki Y, Ishikawa H. (2000). Genome sequence of the endocellular bacterial symbiont of aphids Buchnera sp. APS. Nature 407: 81-86.

Silveira CB, Cardoso AM, Coutinho FH, Lima JL, Pinto LH, Albano RM et al. (2013). Tropical aquatic archaea show environment-specific community composition. PLoS One 8: e76321.

Stamatakis A. (2014). RAxML version 8: a tool for phylogenetic analysis and post-analysis of large phylogenies. Bioinformatics 30: 1312-1313.

Swan BK, Tupper B, Sczyrba A, Lauro FM, Martinez-Garcia M, González JM et al. (2013). Prevalent genome streamlining and latitudinal divergence of planktonic bacteria in the surface ocean. Proc Natl Acad Sci USA 110: 11463-11468.

Takai K, Moser DP, DeFlaun M, Onstott TC, Fredrickson JK. (2001). Archaeal diversity in waters from deep South African gold mines. Appl Environ Microbiol 67: 5750-5760.

Tamas I, Klasson L, Canbäck B, Näslund AK, Eriksson A-S, Wernegreen JJ et al. (2002). 50 million years of genomic stasis in endosymbiotic bacteria. Science 296: $2376-2379$.

Tatusov RL, Galperin MY, Natale DA, Koonin EV. (2000). The COG database: a tool for genome-scale analysis of protein functions and evolution. Nucleic Acids Res 28: 33-36.

Tripathi BM, Kim M, Lai-Hoe A, Shukor NAA, Rahim RA, Go $\mathrm{R}$ et al. (2013). $\mathrm{pH}$ dominates variation in tropical soil archaeal diversity and community structure. FEMS Microbiol Ecol 86: 303-311.

Vetriani C, Jannasch HW, MacGregor BJ, Stahl DA, Reysenbach A-L. (1999). Population structure and phylogenetic characterization of marine benthic Archaea in deep-sea sediments. Appl Environ Microbiol 65: 4375-4384.

Vila-Costa M, Barberan A, Auguet JC, Sharma S, Moran MA, Casamayor EO. (2013). Bacterial and archaeal community structure in the surface microlayer of high mountain lakes examined under two atmospheric aerosol loading scenarios. FEMS Microbiol Ecol 84: 387-397.

Vishnivetskaya TA, Fisher LS, Brodie GA, Phelps TJ. (2013). Microbial communities involved in biological ammonium removal from coal combustion wastewaters. Microb Ecol 66: 49-59.

Visse R, Nagase H. (2003). Matrix metalloproteinases and tissue inhibitors of metalloproteinases: structure, function, and biochemistry. Circ Res 92: 827-839.

Walker CB, de la Torre JR, Klotz MG, Urakawa H, Pinel N, Arp DJ et al. (2010). Nitrosopumilus maritimus genome reveals unique mechanisms for nitrification and autotrophy in globally distributed marine crenarchaea. Proc Natl Acad Sci USA 107: 8818-8823.

Walsh DA, Papke RT, Doolittle WF. (2005). Archaeal diversity along a soil salinity gradient prone to disturbance. Environ Microbiol 7: 1655-1666.

Waters E, Hohn MJ, Ahel I, Graham DE, Adams MD, Barnstead M et al. (2003). The genome of Nanoarchaeum equitans: Insights into early archaeal evolution and derived parasitism. Proc Natl Acad Sci USA 100: 12984-12988.

Wernegreen JJ. (2002). Genome evolution in bacterial endosymbionts of insects. Nat Rev Genet 3: 850-861.

Whitaker RJ, Grogan DW, Taylor JW. (2003). Geographic barriers isolate endemic populations of hyperthermophilic archaea. Science 301: 976-978.

Williams TA, Foster PG, Nye TM, Cox CJ, Embley TM. (2012). A congruent phylogenomic signal places eukaryotes within the Archaea. Proc Biol Sci 279: 4870-4879.

Wrighton KC, Thomas BC, Sharon I, Miller CS, Castelle CJ, VerBerkmoes NC et al. (2012). Fermentation, hydrogen, and sulfur metabolism in multiple uncultivated bacterial phyla. Science 337: 1661-1665.

Yergeau E, Lawrence JR, Sanschagrin S, Waiser MJ, Korber DR, Greer CW. (2012). Next-generation sequencing of microbial communities in the Athabasca River and its tributaries in relation to oil sands mining activities. Appl Environ Microbiol 78: 7626-7637.

Youssef NH, Couger MB, Struchtemeyer CG, Liggenst offer AS, Prade RA, Najar FZ et al. (2013). Genome of the anaerobic fungus Orpinomyces sp. C1A reveals the unique evolutionary history of a remarkable plant biomass degrader. Appl Environ Microbiol 79: 4620-4634.

Yu NY, Wagner JR, Laird MR, Melli G, Rey S, Lo R et al. (2010). PSORTb 3.0: improved protein subcellular localization prediction with refined localization subcategories and predictive capabilities for all prokaryotes. Bioinformatics 26: 1608-1615.

Zuker M. (2003). Mfold web server for nucleic acid folding and hybridization prediction. Nucleic Acids Res 31: 3406-3415.

Supplementary Information accompanies this paper on The ISME Journal website (http://www.nature.com/ismej) 